\title{
The Application of WeChat in a Long-term Mechanism Construction of College Students Education Management
}

\author{
Yanrong $\mathrm{Liu}^{1}$ \\ Xijing University, Xi'an, 710123, China \\ e-mail: 379671328@qq.com
}

\author{
Shidan $\mathrm{He}^{2}$ \\ Xijing University, Xi'an, 710123, China \\ e-mail: 315705804@qq.com
}

\begin{abstract}
As an important part of the construction of spiritual civilization, the education management of college students is related to the cultivation and shaping of the world outlook, outlook on life and values. With the emergence and popularization of micro letters, the freedom of speech is deepened, and the management of the students in colleges and universities is facing unprecedented opportunities and challenges. Based on this background, this paper analyzes the opportunities and challenges faced by the WeChat in the application process of college students education management, and constructs the long-term mechanism of college students' education management, which is designed to provide useful information for personnel training and education in colleges and universities.
\end{abstract}

Keywords-WeChat; College Students; Education ; Management; Build

\section{INTRODUCTION}

At present, human enter the information age, the management work of students in high school should conduct the corresponding ideological preparation and response measures[1]. However, the management of students in colleges and universities is obviously lagging behind the development of the times, the work method is lagging behind and cannot grasp the students' ideological trends, the administrative orders issued by the upload is a lack of a fair and democratic participation of students; education forms and means of a single is a lack of attraction. All the above directly leads to the lack of the students management work, the effectiveness and the relationship between the management and the students, the management of the university students has little effect[2]. Therefore, the management and the students in the common field are fully interactive, extensive participation with certain information platform, which makes the management personnel grasp the student's thoughts, and seize the opportunity to carry out the work of ideological and political education which has become an important work for the management of students in colleges and universities. Group of college students take WeChat as an important media element. WeChat is regarded as a effective platform.[3] Table 1 shows the growth of the number of WeChat users. Germany's famous psychologist, "the father of contemporary experimental social psychology" Lewin Carter cited Einstein's "field is the interdependence of the fact that the definition of the field, he believes that every action is affected by the field, and the field is not only for the physical environment, but also for other factors, only to study the impact of various factors, to reveal the inherent nature of the group[4]. At present, the "WeChat" users are mostly young people, which is based on college students, which shall be paid attention to by the education workers in colleges and universities[5]. WeChat is worth analyzing, which will be helpful to make full use of its advantages, the application in the field of education, and in-depth thinking of the technology.

\section{WeChAT ADVANTAGE}

WeChat originated in 2011, and quickly became a hot social tool. From March to September of 2012, WeChat users increased by nearly one hundred million. According to incomplete statistics, in January 15, 2013, WeChat users exceeded 300,000,000. WeChat version 4.5 released during the Spring Festival of 2013, the number of users quickly exceeded 4 billion. The frequency of use greatly improved by sending Spring Festival greeting letter issued on 26 million. In January 2014, WeChat users reached to 600 million, WeChat has many functions, such as chatting, adding friends, real-time walkie talkies, a circle of friends, voice remind, directory security assistant, QQ mailbox reminder, assistant for private letter, drift bottles, people around, voice notepad, micro blog reading, game center, WeChat public platform and other functions.

In an investigation of the use of WeChat in a university, it can be seen that now almost all college students are using WeChat, as shown in Figure 1[6-7]. Currently, WeChat has evolved from the most popular social information platform to become a major commercial trading platform.

From the application function, as Figure 2 shows, the main features of the $\mathrm{WeChat}$ are as follows:

\section{1) Simple operation}

Friendly and simple interface for each type of user regardless of whether the use of chat tools, can quickly get started, not only through voice, intercom, video chat and other ways to quickly contact each other, but also to share a variety of resources.

\section{2) The use of convenient}

Join the WeChat is no threshold, anyone can through micro signal, QQ number, phone number etc. Adding friends is familiar with the target, which can sweep through and shake, radar etc. Adding strange friends, of 
course, can also pay attention to micro public platform, get more services and information.

\section{3) Mobile portable}

Full use of the mobile terminal portability, without a computer, you can use the mouse and keyboard, which is more suitable for the general public, to the effect of the use of anytime, anywhere.

\section{4) Low cost}

Make full use of the portability of mobile terminals without using computer, mouse keyboard, more suitable for the general public, to achieve the effect of anytime, anywhere.

\section{5) Communication methods}

Support private chat, support group chat, support broadcast, support, etc.

\section{6) Rich communication content}

You can send text, pictures, voice, video and other types of multi type, while the user is concerned about the public platform where there are beautiful graphics and text information

\section{7) High timeliness of interpersonal communication}

Once the message in WeChat will notify the user in the end, with synchronization, so the user is actually forced to read the information sent, the arrival rate of information is almost one hundred percent.

\section{WECHAT IN THE FIELD OF EDUCATION MANAGEMENT IN COLLEGES AND UNIVERSITIES}

WeChat is a product of the mobile Internet to a certain extent, it broke through the time and space constraints, narrowed the distance between people, it has not only changed the way of social interaction, but also changed people's lives, has produced a subtle impact on people in many ways[8]. College workers should be keen to experience this new thing, take full advantage of emerging tools, use a variety of means to achieve the purpose of management and education.

1) To strengthen communication, expand the social intercourse between teachers and students, students and students.

College teaching usually takes the flow of the classroom, the class system, a teaching division may have to face hundreds of students, teacher-student contacts contact opportunity seldom, and it often appear on the teachers cannot call their names and students do not know the names of teachers, which is resulting from the distant relationship between teachers and students, and the strange relationship phenomenon above students is more serious. Although, in the classroom, teachers often talk with students "if the students have any study, life, welcome to communicate with me", but in fact, students rarely through phone calls, visits and other ways to contact the teacher, students and teachers, students and teachers "communication is usually started in the course, and this" exchange "most of the time is" teacher talk, students listen "one-way communication, but only as a necessary condition for the teaching process, and lack of spiritual level. WeChat as a virtual face to face communication tools can improve this situation, through this exchange platform, students should be encouraged to show themselves, communicate, share insights, enhance awareness, and through a certain period of time to focus on a student to speak, but also to find a recent problem[9].

2) Enhance the level of communication between people and people.

Figure 1 shows the use of WeChat in a university news propaganda. And the original popular microblogging is different[10]: in the WeChat platform, can achieve a dialogue of teachers students, "one to many" speaker mode, can also realize teachers students of the "many to many discussion model, also can be achieved between a teacher and a student" point to point "privacy dialogue mode, in a variety of modes of communication can use text, images, audio, video and other various communication carrier and intimate conversations degree more high, more selective.

\section{3) To receive information, provide mobile learning support anytime and anywhere.}

Figure 3 and 4 show the number of WeChat information in colleges and universities, which shows that WeChat has become one of the most important means of propaganda in the University. Teachers can use text, audio, video and other more suitable for mobile learning materials through WeChat group to send their own students, but also through the WeChat will be the answer to the question of specific students; can be through the WeChat and all students to explore common problems, you can also be through the WeChat with a student indepth exchange. And students as long as have a mobile device, you can use the time of fragmentation, in the venue, cafeteria or a specific waiting for the occasion to get their own want to understand the knowledge.

It can be seen from the above analysis the benefits of cloud computing in the teaching, but because some schools have limited funds, technology is limited, it is difficult to achieve the popularization of network teaching and cloud computing in the school, which is the current situation of network teaching in China, the need to continue the development of the good.

IV. SEVERAL CONSIDERATIONS ON THE REASONABLE APPLICATION OF CLOUD COMPUTING IN THE EDUCATIONAL INFORMATIONIZATION

\section{1) Using cloud computing to achieve mobile learning}

In recent years, with the development of mobile technology in China, there is a new way of learning Mobile learning. The so-called mobile learning is to link the mobile terminal with the network facilities from the network platform to obtain the required information resources to learn the way. This new style of learning is not limited by time and region, and can complete the learning process at any time. In cloud computing, there is a huge amount of educational resources, which provides the convenience for mobile learning. Students can learn 
from mobile devices as long as they are able to browse. Of course, educators can also use the education cloud to better complete the teaching.

\section{2) Construction of specialized education in cloud computing services.}

With the development of science and technology and the reform of teaching methods, the Chinese education and research computer network have been set up in China, and have achieved good results in some experimental schools. In addition, in the vocational education industry in the construction industry, Cloud Computing Center, using teach dot.com internal high speed information channel as a guarantee, solves the public cloud caused by network congestion perfectly.

\section{3) Construction of the school cloud computing center.}

Not all applications can run in the public cloud, some special applications need to build their own cloud computing center. Many of the school's applications take up too much of the server or computer, resulting in the waste of resources, to streamline the formation of professional cloud computing center, not only can improve the effective utilization of teaching resources, but also to improve the quality of teaching, should be vigorously implemented.

\section{CONCLUSION}

Cloud computing in teaching the application of information technology will greatly improve the status of education in China, which promotes the development of education, but any kind of thing has its own limitations. Although being versatile, cloud computing can effectively improve teaching efficiency, reduce teaching costs, but still cannot replace the reality of some of the teaching methods. Cloud computing is required to use when its function is selected to maximize the popularity of information technology to promote the education and improvement of education for the progress emitting heat.

\section{FIGURES AND TABLES}

TABLE I THE GROWTH OF WECHAT DATA

\begin{tabular}{|l|l|l|}
\hline Serial number & Time & Content \\
\hline 1 & March 29, 2012 & $\begin{array}{l}\text { WeChat users break 433, time consuming 100000000 days } \\
\text { WeChat user breaking 200000000, time consuming to shorten to } \\
\text { less than 6 months }\end{array}$ \\
\hline 3 & January 15, 2013 & $\begin{array}{l}\text { WeChat users reached 300000000 } \\
\text { WeChat domestic users more than 400000000; in August 15th, the } \\
\text { WeChat overseas users exceeded 100000000 }\end{array}$ \\
\hline 4 & July 25, 2013 & $\begin{array}{l}\text { WeChat 5 on the line, the game center, WeChat payment and } \\
\text { other commercial functions launched }\end{array}$ \\
\hline 5 & August 5, 2013 & $\begin{array}{l}\text { WeChat monthly active users reached 355000000 } \\
\text { WeChat 5.2 release, the interface style of the new revision, with } \\
\text { the trend of the flat; }\end{array}$ \\
\hline 7 & January 28, 2014 & $\begin{array}{l}\text { Tencent announced the launch of the QQ browser WeChat } \\
\text { version; }\end{array}$ \\
\hline 9 & February 20, 2014 & WeChat payment interface officially opened to the outside world \\
\hline 10 & March 19,2014 & WeChat school officially established \\
\hline 11 & April 4, 2014 & WeChat intelligent open platform officially opened \\
\hline
\end{tabular}

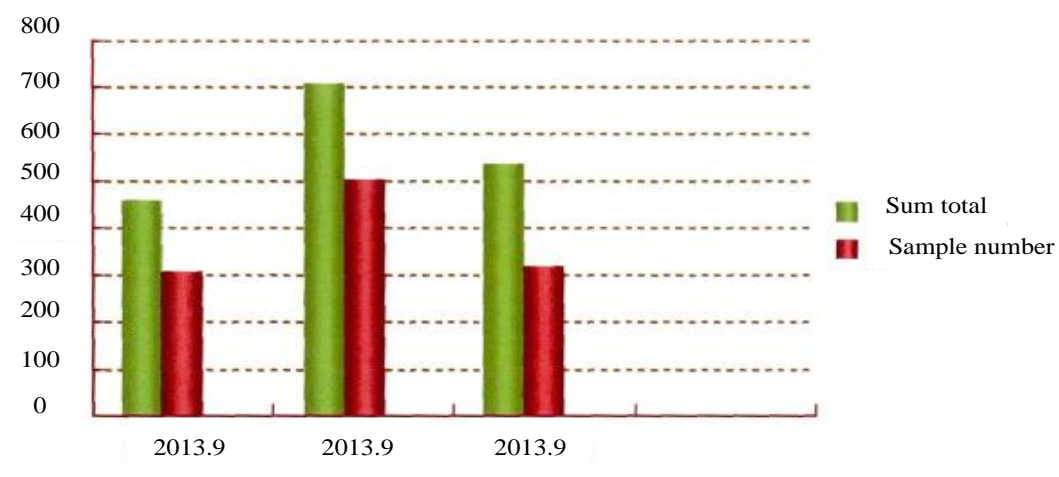

Figure 1. A university news propaganda use of the micro-letter 


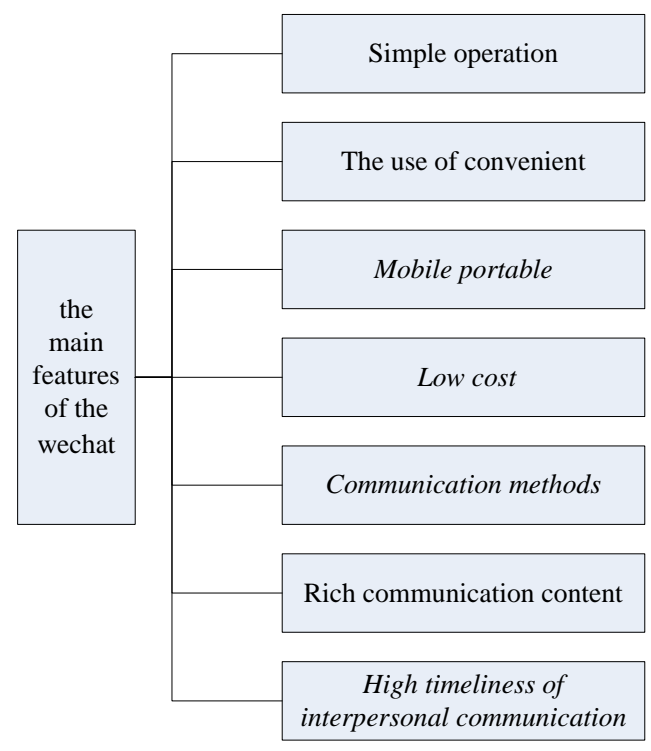

Figure 2. The main features of the WeChat

Do not use $0.00 \%$

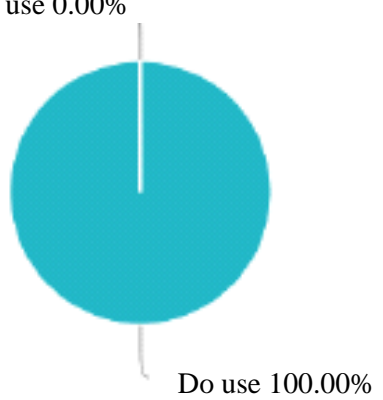

Figure 3. The usage of WeChat of a university student

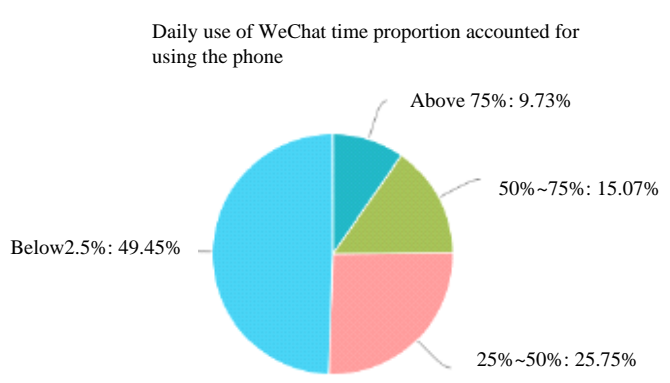

Figure 4. A university student use WeChat proportion

\section{REFERENCES}

[1] Hsu, Yu_Chang;Ching, Yu-Hui. International Review of Research in Open and Distance Learning, v13 n4 p211-227 Oct 2012. (EJ1001713)

[2] Ao, Fei; Luo, Tian; Zhang, Ke. Tweeting for learning: A critical analysis of research on microblogging in education published in 2008-2011. British Journal of Educational Technology. Sep2012, Vol. 43 Issue 5, p783-801. 19p. 1 Diagram, 7 Charts. DOI:10.1111/j. 1467-8535. 2012.01357. x.

[3] BARNES, STUART J. ; BoHRINGER, MARTIN. Journal of Computer Information Systems. Summer2011, Vol. 51 Issue 4,pl10. LOp .

[4] Domizi, Denise P.. TechTrends: Linking Research and Practice to Improve Learning, v57 nl p43_51 Jan 2013. (EJ998568)

[5] Mills, Kathy A. ; Chandra, Vinesh. Journal of Adolescent \& Adult Literacy,v55 nl p35-45 Sep 2011. (EJ960815)
[6] Saunders, Neil; Beltrao, Pedro; Jensen, Lars; Jurczak, Daniel Krause,Roland; Kuhn, Michael; Wu, Shirley. PLoS Computational Biology. Jan2009, Vol. 5 Issue 1, pl-5. 5p. 2 Color Photographs. DOI:10.1371/journal. pcbi. 1000263.

[7] Mills,Kathy A. ; Chandra, Vinesh. Journal of Adolescent \& Adult Literacy.Sep2011, Vol. 55 Issue 1, p35-45. lip. 1 Chart. DOI: 10 1598/JAAL. 55.1. 4

[8] Brink-Drescher, Judy. Microblogging and Lifestreaming in Libraries.Library Journal. 7/1/2010, Vol. 135 Issue 12, p98_98. $1 / 6 \mathrm{p}$.

[9] James Hess, Kayse Shrum. The new media and the acceleration of medical education [J]. On the Horizon,2011, Vol. 19 (4), pp.

[10] Lin Chao-Chen.Convergence of new and old media: new media representation in traditional news[J].Chinese Journal of Communication,2013, Vol.6 (2),pp. 183-201 